\title{
Armchair physics and the method of cases
}

\begin{abstract}
The method of cases, i.e., the informal elicitation of judgements in thought experiments for the purpose of philosophical theorising, has been much criticised in recent years. In this paper we point out that the method of cases is not peculiar to philosophy: it can also be found in physics, where it has made a more limited, but still valuable contribution to the probing and formulation of theories. The method of cases per se should therefore not be treated as intrinsically methodologically flawed. This paper has also a narrower goal: to show that when the analogy underlying the so-called 'expertise defence' is drawn between judgements in thought experiments in philosophy and in physics, several objections can be avoided.
\end{abstract}

\section{Introduction}

Over the last two decades, experimental philosophers have gathered an impressive array of data on judgements in philosophical thought experiments (also known simply as cases). One of the several strands that has been discerned within the experimentalist movement is the so-called "negative programme" (Knobe and Nichols 2017). Proponents of the negative programme have argued that the traditional method of informally eliciting case judgements ${ }^{1}$ from philosophers is deeply flawed (Alexander and Weinberg 2007, Machery 2017): (i) it doesn't take into account the diversity of case judgements of subjects of different demographics and subjects without philosophical training, and (ii) it is ignorant of the sensitivity of case judgements to presentation effects (order and framing of cases).

The conclusions that some proponents of the negative programme have drawn from their results come in varying degrees of scepticism. At the moderate end, experimental philosophers caution against the uncritical use of case judgements and recommend the scientific investigation of when and where case judgements can be used as evidence (Alexander and Weinberg 2007, 2014, Mortensen and Nagel 2016). On the more radical end, philosophers have called for "a radical restriction of the deployment of [case judgements]

\footnotetext{
${ }^{1}$ Oftentimes judgements in cases have been described as "intuitions". But friends and foes of the method of cases have criticised the characterization of these judgements in terms of their psychological properties (Williamson 2007, Cappelen 2012, Machery 2017). Machery (2017) aptly refers to judgements in cases simply as "case judgements".
} 
as evidence" in philosophy (Alexander and Weinberg 2007, 61), and have recommended that we "suspend judgement[s] in response to most philosophical cases", in particular case judgements that are used to support "modally immodest philosophical views" (Machery 2017, 7; see also Machery 2011).

This paper has a narrower and a broader goal. The broader goal of the paper is to stress that philosophers are not alone in using judgements in thought experiments for the purposes of theorising: one can find this practice even in one of our most cherished sciences, namely physics. Since it is undisputed that thought experiments in physics are environments in which reliable judgments can be made, and since thought experiments in physics share many important features with thought experiments in philosophy, there is no ground for thinking that the method of cases is a somehow intrinsically flawed methodological oddity. The narrower goal of the paper is to argue that a popular response to these experimental findings, namely the so-called expertise defence may be better off than sometimes claimed.

The expertise defence has emerged as one of the most popular ways, if not the most popular way, of reacting to the experimental findings regarding case judgements by the 'folk' (see Horvath and Koch forthcoming). Its proponents have argued that the apparent error proneness of case judgements by the folk does not give us a good reason to question the reliability of case judgements by philosophers, just as the error proneness of the folk in matters scientific wouldn't give us a good reason to question the judgements by scientists (Hales 2006, Ludwig 2007, Horvath 2010, Devitt 2011, Williamson 2011). Unfortunately, both the adherents and the critics of the expertise defence have remained rather vague on what kinds of judgements in science the expertise defence builds on. This has resulted in criticism that is threatening to undermine the expertise defence (Ryberg 2012, Nado 2014a, Rini 2014, Nado 2015, Machery 2017). ${ }^{2}$ In this paper, we want to propose that it is best build on judgements in thought experiments in science.

This paper is structured as follows. In Section 2 we show that thought experiments in physics are very similarly structured as thought experiments in philosophy and that judgements in both contexts serve an evidential function. We'll also argue that the epistemology of these judgements is very similar. In Section 3 we'll argue for our broader

\footnotetext{
${ }^{2}$ Other issues have been raised by Weinberg et al. (2010), Machery (2011, 2017).
} 
goal, namely that thought experiments are not intrinsically problematic. In Section 4 we'll argue that the expertise defence can be strengthened by drawing the underlying analogy between judgements in thought experiments. In Section 5 we conclude by pointing to further open issues which the proponents of the expertise defence will still have to address.

\section{Armchair physics}

The purpose of this section is to show that not only in philosophy do many judgements in thought experiments play an evidential role; in many thought experiments in science, too, judgements are treated as evidence. We will first show that judgments in thought experiments in science are often intended as evidence for or against theories in physics, by making a structural comparison between the two kinds of thought experiments and the respective functional place of judgements within thought experiments. Here we can build on extant accounts by Norton (1991, 2004), Häggqvist (2009), and Williamson (2007). Subsequently we will present evidence that judgements in thought experiments in physics have, as a matter of fact, played an evidential role.

\subsection{The structure of thought experiments and the evidential role of judgements}

There is a rich literature on thought experiments in science. However, there is little discussion about judgements in such thought experiments. Instead, philosophers of science have been mostly interested in the nature and function of thought experiments in science. The most prominent views range from constructivist accounts according to which thought experiments are capable of pointing us to weaknesses of current theories (Kuhn 1977, Gendler 1998, Camilleri 2014), to accounts which construe thought experimentation as a form of mental modelling (Nersessian 1992), to Platonist views which conceive of some thought experiments as windows to laws of nature (Brown 1991), and to the view that thought experiments are identical to arguments (Norton 1991, 2004). Although Norton's view has been criticised by many commentators as too restrictive (Bishop 1999, Bokulich and Frappier 2017, Brendel 2017), a weaker thesis, namely that thought experiments can be reconstructed as arguments, strikes us as not too problematic. ${ }^{3}$

\footnotetext{
${ }^{3}$ Norton's stronger thesis actually builds on his weak thesis: he tries to establish the identity thesis largely by challenging his critics to find a thought experiment that cannot be reconstructed as an argument.
} 
Häggqvist (2009), who has analysed one important class of thought experiments in philosophy and in science in terms of counterfactual conditionals (see also Williamson 2007), proposes the following reconstruction:

1. A counterfactual scenario: It is possible that A is the case.

2. The theoretical conditional: If theory $\mathrm{T}$ is true, and if it were the case that $\mathrm{A}, \mathrm{a}$ consequent, $\mathrm{C}$, should be true.

3. A counterfactual conditional: If it were the case that $\mathrm{A}$, it would be the case that not-C.

4. Conclusion (by modus tollens): Therefore, $\mathrm{T}$ is false.

That is, thought experiments, which seek to undermine a theory $\mathrm{T}$, can be reconstructed as consisting of a consideration of a counterfactual scenario, where $\mathrm{A}$ is the case and where it is judged that $C$ is not the case, contradicting a theory that entails $C$. The evidence for the falsehood of $\mathrm{T}$ is provided by the counterfactual judgement that $\mathrm{C}$. This scheme works for thought experiments from science and philosophy alike. Consider for example Schrödinger's cat:

S1. It is possible that a cat can be situated in a way described by the thought experiment.

S2. If the Copenhagen interpretation is true, then, if a cat were situated this way, there is no fact of the matter as to whether the cat is dead or alive.

S3. If the cat were situated in this way, it would have to be either alive or dead.

S4. Therefore, the Copenhagen interpretation is false.

Now consider the notorious Gettier cases:

G1. It is possible for somebody (S) to be in a Gettier situation with regard to $p$.

G2. If knowledge is justified true belief, then if $S$ were in a Gettier situation with regard to $\mathrm{p}, \mathrm{S}$ would know that $\mathrm{p}$.

G3. If $S$ were in a Gettier situation with regard to $p, S$ would justifiably believe the true proposition $\mathrm{p}$ without knowing that $\mathrm{p}$.

G4. Therefore, knowledge is not justified true belief.

Again, in both Schrödinger's cat and the Gettier cases, the relevant counterfactual judgement figures as evidence in the attempted refutation of the theory in question (the Copenhagen interpretation of quantum mechanics and the theory that knowledge is justified true belief, respectively). Although not all thought experiments are meant to refute a theory (some are meant to support theories) ${ }^{4}$, many important ones do fall into that category.

\footnotetext{
${ }^{4} \mathrm{~A}$ thought experiment in physics that supports a theory is e.g. Einstein's elevator. A thought experiment from philosophy may e.g. be Putnam's twin earth supporting the causal theory of reference for natural kinds. See
} 
Let's consider yet another thought experiment from physics, ${ }^{5}$ namely the so-called clock-in-the-box thought experiment, which Einstein used to question the Heisenberg uncertainty relation (see Figure 1).

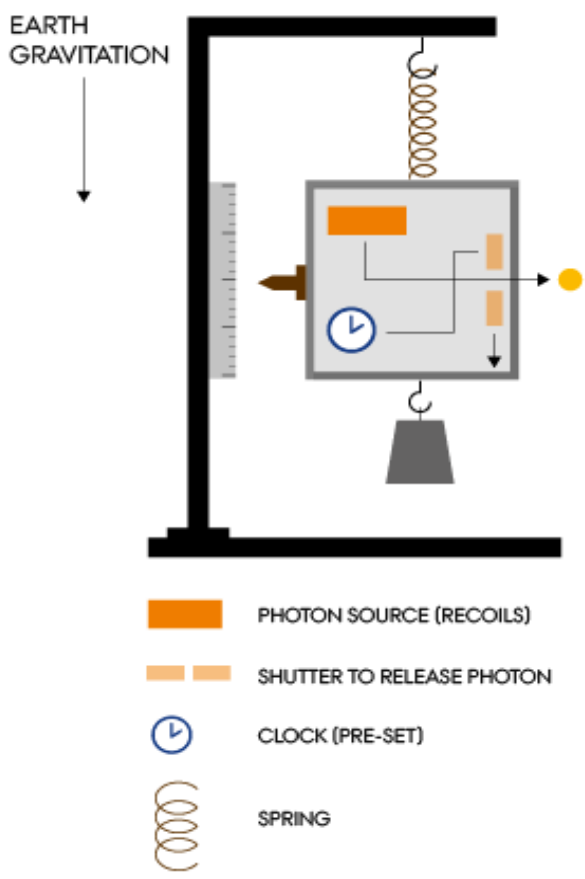

Figure 1: The clock-in-the-box thought experiment. Proposed by Einstein to challenge the Heisenberg uncertainty relation, it was supposed to show that it was possible to measure the energy of a photon at a particular time.

The following reconstruction again follows Häggqvist (2009):

E1. It is possible (in principle) that a single photon exit a box equipped with an arbitrarily exact timer and an arbitrarily sensitive spring-balance.

E2. If the uncertainty principle holds, then the time and energy of its passage would not be simultaneously measurable to any degree of accuracy violating the inequality $\Delta \mathrm{E}$ $\mathrm{x} \Delta \mathrm{t}>\mathrm{h}$ (where $\mathrm{h}$ is Planck's constant / $2 \pi$ ).

E3. If a single photon exited a box equipped with an arbitrarily exact timer and the box were then weighed, the time and energy of its passage would be simultaneously measurable to any degree of accuracy.

E4. Hence, the uncertainty principle doesn't hold.

also Praëm and Steglich-Petersen (2015) for a discussion of constructive and destructive thought experiments in both philosophy and in science.

${ }^{5}$ For some reason, many well-known thought experiments in science are from physics. See Stuart et al. (2017) for (less standard) thought experiments from the other sciences. 
Once again, it is the counterfactual conditional judgement which is meant to provide the evidence on the basis of which a theory (here: an interpretation of quantum mechanics) is questioned. Whether or not the evidence is good, is of course another matter. In this case, it wasn't (see Bishop 1999 for more details). ${ }^{6}$ Regardless, the intended function of the judgement was evidential.

We should say that, more precisely and more correctly, it isn't so much the judgements but rather the content of the judgement that provides evidence for theorising (Williamson 2007, Machery 2017). To see this, consider for example the argument in which one judges that <"Gödel" refers to Gödel and not Schmidt> and where this judgement is the premise for the conclusion that <"Gödel" refers to Gödel and not Schmidt>. In such an argument, the premise (i.e., the judgement) is not available before the conclusion (which the judgement is about). Hence, as long as the conclusion is not asserted or accepted, the premise cannot be true. Accordingly, the judgement cannot serve as evidence for the relevant conclusion; only its content can. For simplicity's sake, however, we shall continue to speak mostly of the evidential function of judgements (rather than of the content of the judgements).

\subsection{Are judgements in thought experiments actually evidential?}

Judgements in thought experiments in physics can have a very similar evidential function as they do in philosophical thought experiments, as we've just seen. But are they also effectively treated as such?

Judgements elicited in philosophical thought experiments have been instrumental in the history of the discipline of philosophy in rejecting previously widely held philosophical views. For example, the relevant judgements in the Gettier cases have been instrumental in undermining the JTB theory of knowledge, Kripke's Gödel cases have helped undermine descriptivism, Mary's room have convinced many that physicalism about the mind is false, etc. Although it has of course been contested by experimental philosophers that judgements elicited by thought experiments ought to be used as evidence, it is denied by few that they have in fact played an evidential role in philosophical practice. That is, it is denied by few

\footnotetext{
${ }^{6}$ It turns out that Einstein ironically ignored relativistic effect that would arise from the movement of the box in a gravitational field, affecting the measurement of the energy of the photon.
} 
that case judgements have historically constituted important reasons for rejecting certain philosophical accounts and supporting others (see e.g. Machery $(2011,2017)){ }^{7}$

So again, in what sense - if any - have judgements in thought experiments in physics played an evidential role in the practice of physics? Clearly, physicists have better sources of evidence at their disposal than judgements in thought experiments, on which they can rely when assessing theories. But this doesn't mean that judgements in thought experiments never serve as evidence in physics. On the contrary, especially in times of theoretical reform judgements in thought experiments can play an important role in highlighting the problems of previous theories and help explore new ones (Kuhn 1977). For example, in the mid-16 ${ }^{\text {th }}$ century Galileo famously showed by means of a thought experiment of two connected falling objects of different weights that there was an inherent contradiction in Aristotelian physics (Gendler 1998). In the late 1920s, Schrödinger used his cat thought experiment (mentioned above) to argue against the plausibility of the Copenhagen interpretation of the new quantum mechanics, and in particular against an ontological interpretation of quantum uncertainty. As he concluded after the presentation of his thought experiment matter-offactly: "That prevents us from so naively accepting as valid a 'blurred model' for representing reality" (Schrödinger 1980, 157).

In a famous debate between Einstein and Bohr concerning the foundations of the new quantum mechanics in the 1920s, Einstein used the aforementioned "clock in the box" thought experiment to challenge Bohr on the plausibility of Heisenberg's uncertainty relation. Bohr's reaction to this thought experiment was not to reject it out of hand because it wasn't a real experiment. On the contrary, Bohr was deeply disturbed by it. As one of his students later reported:

It was quite a shock for Bohr ... he did not see the solution at once. During the whole evening he was extremely unhappy, going from one to the other and trying to persuade them that it couldn't be true, that it would be the end of physics if Einstein were right; but he couldn't produce any refutation. I shall never forget the vision of the two antagonists leaving the club: Einstein a tall majestic figure, walking quietly, with a somewhat ironical smile, and Bohr

\footnotetext{
${ }_{7}^{7}$ Cappelen (2012) has argued that intuitions have not played any evidential role in philosophical theorising. This is controversial. But as far as we are concerned, Cappelen may be right and case judgements still played the evidential role that most philosophers accept they did.
} 
trotting near him, very excited.... The next morning came Bohr's triumph. (Rosenfeld, cited in Pais 1982, 446-7) ${ }^{8}$

That is, Bohr accepted that Einstein's thought experiment elicited the judgement also in him and that the uncertainty relation would be violated in such a scenario. His reported reaction illustrates how seriously he took this thought experiment as evidence against the uncertainty principle (luckily for him, he found a way to avoid this threat (Bishop 1999)).

Of course, this is only anecdotal evidence and a more systematic investigation would be required to assess the actual historical impact thought experiments have had in the relevant contemporary debates. ${ }^{9}$ Yet it seems undeniable that thought experiments were used at crucial junctures of theory formulation and in laying theoretical foundations at times of scientific progress (again see Kuhn 1977). Galileo's thought experiments, for example, were part and parcel of his arguments for a new science of motion (McAllister 2004). Thought experiments such as Schrödinger's cat and Wigner's friend have played a pivotal role in the critical thinking about interpretations of quantum mechanics even long after they were originally advanced.

\subsection{The epistemology of judgements in thought experiments}

In many thought experiments, the truth of the counterfactual judgements cannot be determined on an experimental basis - again, the lack of the appropriate experimental resources is often a reason for resorting to thought experiments in the first place! Moreover, many thought experiments in physics cannot even possibly be carried out in our world. For example, both the already mentioned Einstein's clock-in-the-box and Schrödinger's cat thought experiment describe imaginary scenarios which are practically impossible: it's impossible to build an apparatus that would measure the weight of a photon (photons don't have any mass) and it's impossible to determine the state of the cat in the box without employing some sort of (measurement) interaction. Likewise, in Einstein's famous elevator thought experiment, it seems impossible (by our means) to pull an elevator with a person inside with the required speed through space that has no nearby gravitational fields. But if there is no experimental evidence to determine the right answer of some thought experiments in science, then how do physicists evaluate the truth content of judgements

\footnotetext{
8 See also Bishop (1999) for a philosophical discussion.

${ }_{9}$ Such a systematic historical investigation, as far as we are aware, is not yet available.
} 
about thought experiments in physics? The short answer is: in a similar way as philosophers evaluate the truth content of case judgements, it seems.

As mentioned above, standard accounts reconstruct thought experiments as counterfactual arguments and the ability to 'conduct' thought experiments as the ability to evaluate counterfactual conditionals (Norton 1991, Williamson 2007, Häggqvist 2009). Roughly, when one engages in counterfactual reasoning, one 'enriches' the antecedent via mental simulation and with the help of one's background knowledge. If this enrichment results in the truth of the consequent of the counterfactual, the whole counterfactual conditional is acceptable (Williamson 2007). This seems to be a plausible model not only for thought experiments in philosophy, but also for thought experiments in science. In thought experiments in science one also uses one's imagination and one's background knowledge to produce the relevant scenarios before "one's eyes". Likewise, in thought experiments in science one also needs to judge whether the enrichment of the antecedent of the relevant counterfactual leads to the truth of the consequent. How does one evaluate the truth of a counterfactual?

In accordance with the standard, Lewis-Stalnaker semantics of counterfactuals, a counterfactual is true exactly when the consequent is true in a possible world that is closest to the actual world in which the antecedent is true. ${ }^{10}$ There is one crucial difference between counterfactuals associated with thought experiments in philosophy and science respectively. Thought experiments in philosophy often not only diverge from the actual facts but also violate the laws of nature. Metaphysically possible worlds are therefore often more relevant than physically possible worlds in the assessment of the relevant counterfactual. In contrast, in thought experiments in science the laws of nature set strong constraints on what is considered possible-even if many thought experiments in physics are not actually physically possible, given the physical facts of this world (our limited ability to produce energy, for example). Regardless, the metric and the procedure for evaluating the closeness of any of such worlds in a semantics of counterfactuals should be the same.

One may be tempted to think that, perhaps, in philosophical thought experiments one can evaluate the truth of the relevant counterfactual without considering any kind of

\footnotetext{
10 The account provides a "similarity metric", i.e., a set of criteria on the basis of which one can evaluate how close a possible world is to the actual world.
} 
empirical knowledge, whereas in physics the only relevant facts are the empirical ones. But neither of these things is quite true. Even though we're often interested in metaphysically (or logically) possible worlds in philosophical thought experiments, the evaluation of the relevant counterfactual is often a posteriori; we have to consult our background knowledge about the actual world in order to be able to judge whether the worlds considered are sufficiently similar (Williamson 2007). On the other hand, in thought experiments in physics, one often has to abstract away from the actual matters of facts and focus merely on whether or not a situation is physically possible by virtue of the laws of nature. So both thought experiments in philosophy and thought experiments in physics are neither "fully" a priori nor fully a posteriori.

Let us take stock. We have seen that judgements in many thought experiments in philosophy and physics serve the same function (as evidence in arguments against some theory) and that judgements in both kinds of thought experiments have a similar epistemology. In the following two sections we will build on these results to argue for the broader and narrower goal of this paper: there is nothing intrinsically suspect about case judgements, and the expertise defence can be strengthened by drawing the underlying analogy between judgements in thought experiments in philosophy and physics.

\section{The broader goal: no intrinsic flaws in the method of cases}

As mentioned in the introduction of this paper, the negative programme in experimental philosophy has drawn rather pessimistic conclusions about the epistemic prospects of case judgements. The critics are quite adamant that their scepticism about case judgements does not extend to other forms of judgements (Machery 2011, 2017). But what is it that makes specifically case judgements, rather than some other forms of judgements, problematic as a source of information for philosophical theorising? Some proponents of the negative programme have taken it upon themselves to identify reasons for why this may be so.

Machery (2017) identifies three "disturbing characteristics" of philosophical cases, which he suggests are responsible for the "fundamental unreliability" of case judgements (111-120): cases are (i) unusual, (ii) pull apart properties that usually go together, and (iii) contain "superficial content". ${ }^{11}$ Cases are unusual in that, for example, body- and brain-

\footnotetext{
${ }^{11}$ Machery doesn't think that all of these characteristics are required in a particular case to cause the unreliably of judgments nor that any one of these characteristics would necessitate judgments to be unreliable. But he does
} 
swapping cases ask subjects to assess situations they may have never read or thought about before. Cases pull apart properties in that, for example, we are asked to consider cases in which causing harm can actually do more good than bad, as in the notorious trolley cases. In Gettier cases, the "usual strategies" of identifying knowledge may fail because some crucial properties of the belief forming process that normally hold (e.g. safety) do not hold in these cases. Cases contain superficial content, that is, narrative content that is irrelevant to the philosophical point in question and that may distract subjects from what's at stake. For example, in Gettier cases, it doesn't matter whether the scenario is about somebody in the office driving a brown Ford or about a broken clock showing the right time. In sum, Machery argues that the epistemic uncertainty associated with these three "disturbing characteristics" is likely to result in individual differences in subjects' responses and to make subjects' responses sensitive to confounders.

Machery singles out specifically philosophical thought experiments as environments that cause the unreliability of judgements. Yet physical thought experiments exhibit all the very characteristics that Machery describes as "disturbing". For example, Schrödinger's cat is a highly 'unusual' scenario in Machery's sense (we infrequently encounter it and rarely read texts about it). That is, it is highly unusual for cats to be trapped in a box with mechanisms that have a certain probability of killing them. Properties that usually go together are also being pulled apart. That is, quantum mechanical properties are usually associated with micro-objects like electrons and photons, not so much with cats. Finally, Schrödinger's cat also contains plenty of narrative detail irrelevant to the point under consideration: it is irrelevant whether the animal in the box is actually a cat, a dog, or another animal entirely, it is irrelevant what exactly the mechanism is that would kill the animal (e.g. poison or an explosion), etc.

We seem to be faced with the following options: either Machery is right that thought experiments in philosophy exhibit disturbing characteristics that cause the unreliability of case judgements or he isn't. If he's right, then we seem forced to conclude that thought experiments in physics, by virtue of them exhibiting the very same characteristics that we find in philosophical cases, too should be environments which cause judgements to be

believe that at least one of these characteristics cause unreliable judgments in philosophical cases (Machery 2017, 112). 
unreliable. But this seems too strong. Although there are clearly some thought experiments in physics that may be considered misleading or even "failed" (Norton 2004, 2017), there are also very successful ones - some of which we discussed - which elicit judgements that have served as important, and good reasons for rejecting or clarifying the targeted physical theories. In the philosophical literature on thought experiments in science, there has been no dispute about whether thought experiments can be environments for drawing truthconducive inferences; the dispute is mostly about how that is possible (Norton 2004, Stuart et al. 2017). ${ }^{12}$ Thus, since thought experiments in physics are well capable of allowing for reliable inferences and judgments, and since thought experiments in physics exhibit the very same features that we find in thought experiments in philosophy, those features can't really be the causes of the alleged general unreliability of the judgements. Hence, a general scepticism about judgements in thought experiments on the basis of the characteristics of thought experiments is unwarranted.

Perhaps there are some other reasons than the features of philosophical thought experiments that cause judgements in these environments to be unreliable. However Machery's proposal is the only proposal experimental philosophers have made to support their scepticism about case judgements. Or perhaps it is not the features of thought experiments that are to blame for the unreliability of case judgements, but rather the subjects making the judgements. This is what the so-called expertise defence says: laypeople's judgements in thought experiments may be unreliable, but there is little evidence or reason to think that the experts' judgements are as unreliable as claimed. Since most experimental studies to date are indeed still studies that have been conducted with the folk, ${ }^{13}$ the expertise defence is still a live option. Although there have been experimental work also with philosophers as subjects, many of those are not as compelling as sometimes claimed, as we will argue in Section 4.2. At first, though, we will set our focus on strengthening the expertise defence in the light of our discussion in Section 2.

\footnotetext{
12 There is now even some experimental evidence that judgements made by physicists in thought experiments in physics are reliable (Schindler and Saint-Germier 2020).

${ }^{13}$ For example, Machery, in the chapter entitled "The empirical findings" of his recent book, summarises all previous experimental work that has used exclusively laypeople as subjects (Machery 2017).
} 


\section{The narrower goal: strengthening the expertise defence}

A central way in which the expertise defence is motivated is by analogy to other fields of expertise such as mathematics, physics, linguistics and palaeontology (Hales 2006, Ludwig 2007, Horvath 2010, Devitt 2011, Williamson 2011). The defence suggests that it would strike us as outright absurd to think that, for example, the expertise to accurately perform mathematical operations or the ability to construct proper physical experiments should in any way be undermined by experiments showing that the folk diverge significantly in their responses when asked about a mathematical problem, the setting up of a physical experiment, and so on. Why, the proponents of the expertise defence ask, should we then be disturbed if experiments showed that case judgements of laypeople were unreliable?

While most proponents of the expertise defence draw the analogy to natural science or math, they have appealed to a (just mentioned) motley bunch of science expert judgements. For the analogy to be convincing, however, the similarities between expert judgements must be of the right kind. For example, drawing an analogy between apples and oranges might be quite mistaken when drawn between the constitution of the inner parts of these fruits, but the analogy could also be quite acceptable (despite the proverb), for example, when the analogy is drawn between the shapes of those fruits. Is the analogy underlying the expertise defence of the right kind? This has been denied by Nado (2014a, 2015), Ryberg (2012), Rini (2014), and Machery (2017). Here we will show that the expertise defence can avoid some of these criticisms if the analogy is drawn not just between case judgements in philosophy and (generic) judgements in science, but rather, between case judgements and judgements in thought experiments in science.

\subsection{How to avoid objections to the analogy}

Nado (2014a, 2015) offers perhaps the most comprehensive criticism of the analogy underlying the expertise defence. ${ }^{14}$ In particular, Nado has argued that expert judgements in science - such as a physicist's judgement that a moving object will follow a certain trajectory - (i) are reflective (rather than intuitive), (ii) are based on explicitly accessible and learned principles (rather than on opaque ones), (iii), do not function as evidence for theories. Nado takes these three points to show that not only the analogy fails, but also that

\footnotetext{
${ }^{14}$ Ryberg (2012) and Rini (2014) focus on the expertise defence in the moral realm. See also Andow (2015) for a critique of the Ryberg.
} 
it's implausible that philosophers would be better than the folk at controlling confounders of their case judgements (as argued by the expertise defence). She also adds that, in contrast to philosophers, scientists have developed methods for controlling their own biases. Until philosophers have developed "similar compensatory procedures", she claims, the expertise defence doesn't have much plausibility (Nado 2015, 1035).

In what follows we will show that Nado's three points of criticism do not apply when the analogy is drawn between case judgements and judgements in thought experiments in physics (rather than some generic and vague category of 'scientific judgements'). Let us consider Nado's three points in more detail in turn.

First, Nado (2015) argues that, in contrast to case judgements (or intuitions) in philosophy, which are "immediate and unreflective" (1032) and made "in the absence of introspectively obvious conscious reasoning" (1029), judgements in science are reflective judgements (1032). However, Nado herself points out that this difference is not accepted by people like Devitt who hold that philosophical (and linguistic) judgements are theory-laden and that can be improved by better theories (Devitt 2010, 2011). ${ }^{15}$ Likewise, philosophers who do not think that case judgements should be defined in terms of their psychological properties (e.g., Williamson (2007), Cappelen (2012), and Machery (2017)) would probably not accept that a contrast between "intuitive" and "reflective" adequately captures a difference between case judgements and judgements in science. ${ }^{16}$

Even if one were to accept Nado's distinction between intuitive and reflective judgements, it looks as though there are judgements in thought experiments in physics, which satisfy Nado's first class of judgements - the class, that is, which she reserved for philosophical case judgements. It is for example intuitive that Schrödinger's cat is alive or dead even before we open the box. It is also intuitive that the Stevin's chain will not move (Figure 2) and that the objects on Galileo's ship will follow the same trajectories as when dropped on a stationary ship (see also below).

\footnotetext{
${ }_{15}$ See Colaço et al. (ms) for a detailed critical discussion and an empirical test of this claim.

16 Williamson (2007) warns against "psychologising the data" in the method of cases (5) and proposes to get rid of the term 'intuition' altogether (220). Cappelen (2012) argues that intuitions play no substantive role in philosophical practice. Machery (2017) rejects psychological characterizations and prefers to speak of case judgements (as we do). See also fn. 1.
} 
Second, Nado argues that scientific judgements are "mediated by explicit beliefs and theories acquired in the classroom", whereas case judgements are not (Nado 2015, 1032). Scientists accordingly have "explicit access" to principles justifying their judgements and those principles are "consciously available and straightforwardly articulable" (1033). In contrast, in philosophy, these principles are "frustratingly opaque" (1033). For example, when they judge the shape of the trajectory of a cannon ball, physicists can justify their judgements in a way that philosophers cannot, namely by appealing to the well-established principles of Newtonian mechanics. No such principles are available for case judgements, Nado claims, because if they were, "we likely could have avoided, for instance, several decades of post-Gettier literature" (1033).

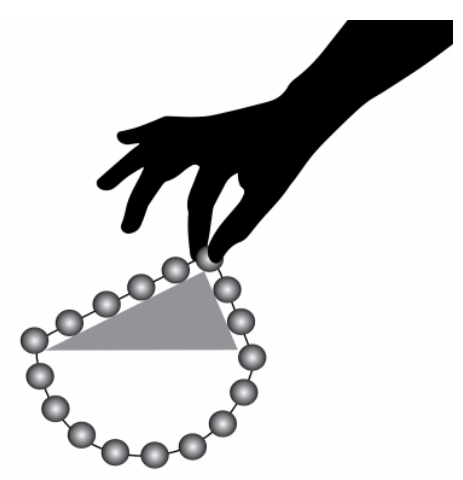

Figure 2: Stevin's chain. Does a chain of evenly divided balls draped over two inclined planes start moving to the right or left under its own weight? No, Stevin argued, because if it would, and each ball the chain had moved to the position of the previous ball, the chain would be indistinguishable from its initial position and the movement shall continue indefinitely, in contradiction with the impossibility of perceptual motion machines.

Nado's assessment applies to (generic) judgements in science, such as predicting the path of a projectile. But consider now judgements in thought experiments in science. Are the principles that underlie judgements in thought experiments in science always transparent and accessible to those making the judgements? It seems not. For example, in order to demonstrate that a moving earth was reconcilable with the manifest physics, Galileo in Day Two of his Dialogue Concerning the Two Chief World Systems invited his readers to "shut yourself up with some friend in the main cabin below decks on some large [moving] ship" and to observe the motion and trajectories of various objects, such as a fish in a water tank, water drops from a bottle falling on the floor, a ball thrown to a 'friend', etc. Since the physics on a uniformly moving ship (under ideal conditions) is indistinguishable from one that is standing still, there is every reason to think that a moving earth shouldn't imply a different physics than the one that manifests itself to us. The principle justifying the judgement (that the physics on a moving ship is no different from a standing ship, or more 
generally that the laws of motion are the same in all inertial frames) became to be known as Galilean invariance.

When Galileo proposed his thought experiment, this principle was only informally and intuitively available to Galileo; he had no means for expressing it formally as part of a theory of motion. Likewise, the intended judgement in so-called Stevin's chain (1586), presupposes the principle that perpetual motion machines are impossible (see Figure 2). The theory of thermodynamics, which rules out perpetual motion machines, however, would not be formulated until the early $19^{\text {th }}$ century. In yet other thought experiments in science, it's actually quite obscure what the principles might be that underlie the relevant judgements. For example, what is the principle that underlies the judgement that Schrödinger's cat is either dead or alive, even before the box is opened? Some kind of principle of familiarity with everyday experience?

In sum, the principles underlying judgements in thought experiments in physics are not as transparent as Nado makes them out to be in her comparison of (generic) judgements in science and case judgements. Conversely, one may also question whether the principles underlying case judgements are really always as "frustratingly opaque" as Nado claims. In Gettier cases, which Nado singles out specifically, we have all developed a sense that the reason we make the judgement that "Smith doesn't know" has got something to do with the widely accepted fact that one cannot know by luck. Overall then, expert judgements in philosophy and in science can be quite similar with regard to their (in-)transparency.

Apart from the question of transparency of principles underlying judgements, there is another issue implicit in Nado's second critique. Nado implies that in science, the learned and explicitly accessible principles help scientists to avoid bias and mistakes (whereas no such principles are available in philosophy). But that is only the case, if these principles are (approximately) true and they are known to be true. Only then can one disqualify a judgement (say, about the shape of a projectile) as being erroneous, when it violates such principles, or when it is based on the wrong principles. In the context of thought experiments, however, this assumption is highly problematic. As we've mentioned already in Section 2.2, thought experiments have been proposed in historical periods in which the theoretical foundations of the science in question were very much in doubt and new ideas yet still to be proven (Kuhn 1977). For example, the early $20^{\text {th }}$ century witnessed a flurry of 
thought experiments when classical physics made way for quantum mechanics and the theory of relativity. Many of the most well-known thought experiments in physics in fact stem from this period: Schrödinger's cat, the clock-in-the-box, the Einstein-Podolsky-Rosen paradox, Einstein's elevator, Einstein's twins, etc. Other famous thought experiments stem from what we know as the scientific revolution: Galileo's tower and ship thought experiments, and Newton's bucket and cannon (for details see e.g. Brown and Fehige 2019 and Stuart et al. 2017). In these revolutionary periods, thought experiments were used to convince sceptics that the new science could make sense of previous obstacles such as "why do objects, when shot vertically up in the air, not land to the west from where they departed, if the earth really would rotate eastward?" (a great concern of Galileo), or how circular planetary motion could be accommodated with terrestrial physics (as neatly illustrated by Newton's cannon). It is in these revolutionary periods of science scientists could not appeal to the truth of the principles underlying their judgements, since this still had yet to be established.

Third, Nado identifies a "crucial methodological difference" between scientific judgements and philosophical judgements in cases: whereas armchair philosophers often treat case judgements as (defeasible) evidence for philosophical theories, judgements in science are not used to support scientific theories. Instead, theories are used to support judgements. As Nado says, "the support goes the other way round" (1033).

We've already seen in detail in Section 2 that judgements in thought experiments in science also serve an evidential function. That is, the judgement that the cat in Schrödinger's thought experiment is either dead or alive is meant to undermine the Copenhagen interpretation of quantum mechanics. The judgement that, in some scenarios, the energy of a photon can be measured at a particular time was supposed to undermine the Heisenberg uncertainty relation. So in thought experiments in physics, the evidential support does often run in the right direction (from judgement to theory, not the other way around).

Of course, physicists are much less dependent on judgements in thought experiments than philosophers are: physicists can often conduct actual experiments to probe their arguments. In fact, there are important thought experiments (such as the Einstein-PodolskyRosen paradox), (parts of) which were successfully translated into an actual experimental 
set up (Aspect 1999). There are however other thought experiments, where actual experiments are not (and probably never will be) available (see Section 2.3 for examples).

Regardless of whether thought experiments in physics will eventually be realised or whether other (better) evidence sources become available, it is important to note once more that in their original historical contexts, these additional evidence sources were not available. It is in these contexts in which judgements in thought experiments fulfil their (intended) evidential function.

To the three points just discussed, Nado adds that judgements in science are different from judgements in philosophy in that scientists have successfully developed by methods for controlling biases affecting their judgements, such as double-blinding and randomization. Philosophers are yet to come up with "similar compensatory procedures" in philosophical practice (Nado 2015, 1035). ${ }^{17}$ Although this is correct as far as many scientific judgements are concerned, things look different when it comes to thought experiments in science. Quite in contrast to real experiments, there is no obvious sense in which thought experiments could be controlled, for example, by double-blinding or randomization.

In sum, the objections that Nado and others have raised against the analogy underlying the expertise defence can be avoided if the analogy is drawn between case judgements and judgements in thought experiments in science (in particular in physics). Combined with a recently published result that physicists are indeed better at judging thought experiments in physics than the folk, the expertise defence seems considerably strengthened. But is it still relevant?

\subsection{On the relevance and prospects of the expertise defence}

Although it is sometimes claimed that the expertise defence has been defeated (Nado 2015, Machery 2017, Horvath and Koch forthcoming), we believe that the death knells have been rung prematurely. First of all, the vast majority of the experimentalist challenge to the method of cases has come from studies with students or Amazon Turk subjects (Machery 2017 $)^{18}$. Here the expertise defence applies rather straightforwardly. However there have

\footnotetext{
17 Similarly, Machery (2017) criticises the analogy underlying the expertise defence by pointing out that whereas scientists "have extensively calibrated their instruments ... there is nothing analogous with respect to the cases used by philosophers" (161).

18 See footnote 13.
} 
also been studies with professional philosophers (Schulz et al. 2011, Machery 2012, Schwitzgebel and Cushman 2012, Tobia et al. 2013, Vaesen et al. 2013, Horvath and Wiegmann 2016, Wiegmann and Horvath forthcoming). Here the expertise defence seems to be in significant trouble.

It is worth noting that most of the extant studies with philosophers concern cases from the moral realm. For example, Schwitzgebel and Cushman (2012) and Tobia et al. (2013) present data showing that even the moral intuitions of philosophers are susceptible to order effects and framing effects, respectively. For all that we know, however, case judgements may be generated by different mental capacities and may therefore have different degrees of reliability (Nado 2014b). Rini (2014) in fact singles out specifically moral philosophy as a domain in which the expertise defence may be applicable only with certain caveats. So even though the expertise defence may have lost plausibility at this point with regards to moral judgements, it still seems to be a live option with regards to other kinds of philosophical judgements.

To date, there are still only a handful of studies with philosophers on non-moral judgements (Machery 2012, Vaesen et al. 2013, Horvath and Wiegmann 2016, Löhr 2019, Starmans and Friedman 2020). Let us briefly comment on each of these studies:

- In Machery's study on reference, the majority of experts from linguistics and philosophy report the standard Kripkean judgement (Machery 2012). The proportion varies across groups (66.7\% to $88.6 \%$ ), with philosophers and semanticists being more likely to report the standard Kripkean judgement than linguists with other specialisations. Machery claims that this is evidence against the expertise defence, since linguists specialising in historical and anthropological linguistics are just as concerned with reference as philosophers and semanticists. This is debatable though (see also Devitt 2012).

- Horvath and Wiegmann (2016), in their study on (non-)knowledge cases, found in agreement with the expertise defence that philosophers in the majority of cases agreed with what they referred to as the "textbook consensus" about case judgements and the folk didn't. However, they found that even though experts' responses in fakebarn scenarios were on average closer to the disagree end of the scale than the folk's responses with regards to knowledge ascriptions (as expected), more experts agreed than disagreed with the textbook consensus (contrary to expectation). 
- Starmans and Friedman (2020) present evidence that not only the folk but also other academics are more likely to attribute knowledge in Gettier cases than philosophers. They suggest that philosophers' concepts of "knowledge" and "mere belief" may therefore be no more than an idiosyncratic artefact of their training, rather than a product of their expertise. In the light of the preponderance of evidence in favour of the Gettier intuition also among the folk even from different culture (Nagel et al. 2013, Turri 2013, Machery et al. 2017), such a view doesn't seem very plausible.

- Vaesen et al. (2013) present evidence that philosophers' judgement varies with their native language. However, the study is problematic in that it doesn't seem to be about case judgements in the first place, but rather about judging stipulations. So, for example, instead of asking subjects about some version of Gettier cases, subjects were asked to judge whether "Steffi knows" qualifies as knowledge in a sentence like "Steffi knows that water is $\mathrm{H}_{2} \mathrm{O}$ ". There was no scenario in which Steffi knew that water is $\mathrm{H}_{2} \mathrm{O}$ merely by luck. Furthermore, it is possible that the meaning of the prompts was significantly altered across the different languages. ${ }^{19}$

- Löhr (2019) shows that not only the folk, but also the philosophers make seemingly inconsistent judgements in different versions of Novick's "experience machine". Since the difference between the scenarios are rather substantial, it may be the case though that the different case judgements actually track philosophically relevant differences.

Thus, although the expertise defence does seem to be in trouble with regards to moral case judgements, the case still has to be made that other kinds of case judgements are similarly problematic when made by trained philosophers.

\section{Conclusion}

This paper pursued a broader and a narrower goal. The broader goal was to show that the method of cases should not be treated as methodological abnormality that is somehow intrinsically problematic. We argued this by pointing out that thought experiments in physics exhibit the very same features that have been identified as causing case judgments in philosophy to be unreliable. Since there is no dispute about thought experiments in

\footnotetext{
${ }^{19}$ This turned out to be a problem in some replication studies in psychology (see Earp and Trafimow 2015).
} 
physics being environments that allow for reliable judgments, the features in question cannot be the causes for the general unreliability of case judgements either. It is for the sceptics to come up with other proposals for why we should be sceptical specifically about case judgments. Alternatively, experimental results are accounted for by the unreliability of the subjects that have been used predominantly hitherto, namely laypeople. The few studies that have been conducted with philosophers, we argued, have not convincingly shown that philosophers are as much subject to confounders as the folk - except perhaps moral philosophy.

Our narrower goal in this paper was to show that several objections against the expertise defence can be avoided by drawing the underlying analogy between case judgements and judgements in thought experiments in physics. The prospects of the expertise defence are thus in sum much better than often claimed (Nado 2015, Machery 2017, Horvath and Koch forthcoming).

We don't pretend to have delivered a blanket victory to the defenders of traditional philosophical methodology; there are still many open issues, such as whether it actually makes sense to talk about genuine expertise in making judgements in philosophical cases (Machery 2017). We do believe, though, that we have clarified the basis on which the debate of the expertise defence should take place.

\section{References}

Alexander, Joshua and Jonathan M Weinberg. 2007. Analytic epistemology and experimental philosophy. Philosophy Compass, 2 (1): 56-80.

- - - 2014. The "unreliability" of epistemic intuitions. In Current Controversies in Experimental Philosophy, Edouard Machery and Elizabeth O'Neill (eds.), New York: Routledge, 128-145.

Andow, James. 2015. Expecting moral philosophers to be reliable. Dialectica, 69 (2): 205-220. Aspect, Alain. 1999. Bell's inequality test: more ideal than ever. Nature, 398 (6724): 189-190. Bishop, Michael A. 1999. Why thought experiments are not arguments. Philosophy of Science, 66 (4): 534-541.

Bokulich, Alisa and Mélanie Frappier. 2017. On the Identity of Thought Experiments: Thought Experiments Rethought. In The Routledge companion to thought experiments, Michael T Stuart, Yiftach Fehige and James Robert Brown (eds.), London: Routledge, 545-557. 
Brendel, Elke. 2017. The Argument View. Are thought experiments mere picturesque arguments? . In The Routledge companion to thought experiments, Michael T Stuart, Yiftach Fehige and James Robert Brown (eds.), London: Routledge, 281-291.

Brown, James Robert. 1991. The Laboratory of the Mind: Thought Experiments in the Natural Sciences. New York: Routledge.

Camilleri, Kristian. 2014. Toward a constructivist epistemology of thought experiments in science. Synthese, 191 (8): 1697-1716.

Cappelen, Herman. 2012. Philosophy without intuitions. Oxford: Oxford University Press.

Colaço, David, Markus Kneer, Joshua Alexander, et al. ms. On second thought: A refutation of the reflection defense. https://doi.org/10.13140/rg.2.2.34481.68967

Devitt, Michael. 2010. Linguistic intuitions revisited. The British Journal for the Philosophy of Science, 61 (4): 833-865.

- - . 2011. Experimental semantics. Philosophy and Phenomenological Research, 82 (2): 418435.

- - . 2012. Whither experimental semantics? THEORIA. Revista de Teoría, Historia y Fundamentos de la Ciencia, 27 (1): 5-36.

Earp, Brian D and David Trafimow. 2015. Replication, falsification, and the crisis of confidence in social psychology. Frontiers in psychology, 6: 621.

Gendler, Tamar Szabó. 1998. Galileo and the indispensability of scientific thought experiment. The British Journal for the Philosophy of Science, 49 (3): 397-424.

Häggqvist, Sören. 2009. A model for thought experiments. Canadian Journal of Philosophy, 39 (1): 55-76.

Hales, Steven D. 2006. Relativism and the Foundations of Philosophy. Cambridge, MA: MIT Press.

Horvath, Joachim. 2010. How (not) to react to experimental philosophy. Philosophical Psychology, 23 (4): 447-480.

Horvath, Joachim and Steffen Koch. forthcoming. Experimental philosophy and the method of cases. Philosophy Compass.

Horvath, Joachim and Alex Wiegmann. 2016. Intuitive expertise and intuitions about knowledge. Philosophical Studies, 173 (10): 2701-2726.

Knobe, Joshua and Shaun Nichols. 2017. Experimental Philosophy. The Stanford Encyclopedia of Philosophy (Winter 2017 Edition), edited by Edward N. Zalta, https://plato.stanford.edu/archives/win2017/entries/experimental-philosophy/.

Kuhn, Thomas S. 1977. A function for thought experiments. In The Essential Tension, Thomas S. Kuhn (ed.), Chicago: University of Chicago Press, 240-265.

Löhr, Guido. 2019. The experience machine and the expertise defense. Philosophical Psychology, 32 (2): 257-273.

Ludwig, Kirk. 2007. The epistemology of thought experiments: First person versus third person approaches. Midwest Studies in Philosophy, 31 (1): 128-159.

Machery, Edouard. 2011. Thought experiments and philosophical knowledge. Metaphilosophy, 42 (3): 191-214. 
- - - 2012. Expertise and intuitions about reference. THEORIA. Revista de Teoría, Historia y Fundamentos de la Ciencia, 27 (1): 37-54.

- - - 2017. Philosophy within its proper bounds: Oxford University Press.

Machery, Edouard, Stephen Stich, David Rose, et al. 2017. Gettier across cultures. Noûs, 51 (3): 645-664.

McAllister, James W. 2004. Thought experiments and the belief in phenomena. Philosophy of Science, 71 (5): 1164-1175.

Mortensen, Kaija and Jennifer Nagel. 2016. Armchair-Friendly Experimental Philosophy. A Companion to Experimental Philosophy: 53-70.

Nado, Jennifer. 2014a. Philosophical Expertise. Philosophy Compass, 9 (9): 631-641.

- - - 2014b. Why intuition? Philosophy and Phenomenological Research, 89 (1): 15-41.

- - - 2015. Philosophical expertise and scientific expertise. Philosophical Psychology, 28 (7): 1026-1044.

Nagel, Jennifer, Valerie San Juan, and Raymond A Mar. 2013. Lay denial of knowledge for justified true beliefs. Cognition, 129 (3): 652-661.

Nersessian, Nancy. 1992. In the theoretician's laboratory: thought experimenting as mental modeling. PSA: Proceedings of the Biennial Meeting of the Philosophy of Science Association, 2: 291-301.

Norton, John D. 1991. Thought experiments in Einstein's work. In Thought Experiments in Science and Philosophy, T. Horowitz and Gerald J. Massey (eds.), Savage, MD: Rowman and Littlefield, 129-148.

- - - 2004. Why Thought Experiments Do Not Transcend Empiricism. In Contemporary Debates in the Philosophy of Science, Christopher Hitchcock (ed.), Oxford: Blackwell, 44-66.

- - . 2017. The worst thought experiment. In The Routledge companion to thought experiments, Michael T Stuart, Yiftach Fehige and James Robert Brown (eds.), London: Routledge, 454-468.

Pais, Abraham. 1982. Subtle is the Lord: The Science and the Life of Albert Einstein: The Science and the Life of Albert Einstein. New York: Oxford University Press.

Praëm, Sara Kier and Asbjørn Steglich-Petersen. 2015. Philosophical thought experiments as heuristics for theory discovery. Synthese, 192 (9): 2827-2842.

Rini, Regina A. 2014. Analogies, moral intuitions, and the expertise defence. Review of Philosophy and Psychology, 5 (2): 169-181.

Ryberg, Jesper. 2012. Moral intuitions and the expertise defence. Analysis, 73 (1): 3-9.

Schindler, Samuel and Pierre Saint-Germier. 2020. Are thought experiments "disturbing"? The case of armchair physics. Philosophical Studies, 177: 2671-2695.

Schrödinger, Erwin. 1980. The Present Situation in Quantum Mechanics. A Translation of Schrodinger's "Cat Paradox" Paper. (Trans. John D. Trimmer) Proceedings of the American Philosophical Society, 124: 323-338. 
Schulz, Eric, Edward T Cokely, and Adam Feltz. 2011. Persistent bias in expert judgments about free will and moral responsibility: A test of the expertise defense. Consciousness and Cognition, 20 (4): 1722-1731.

Schwitzgebel, Eric and Fiery Cushman. 2012. Expertise in moral reasoning? Order effects on moral judgment in professional philosophers and non-philosophers. Mind $\mathcal{E}$ Language, 27 (2): 135-153.

Starmans, Christina and Ori Friedman. 2020. Expert or esoteric? Philosophers attribute knowledge differently than all other academics. Cognitive Science, 44 (7): e12850.

Stuart, Michael T, Yiftach Fehige, and James Robert Brown, eds. 2017. The Routledge companion to thought experiments. London: Routledge.

Tobia, Kevin, Wesley Buckwalter, and Stephen Stich. 2013. Moral intuitions: Are philosophers experts? Philosophical Psychology, 26 (5): 629-638.

Turri, John. 2013. A conspicuous art: putting Gettier to the test. Philosophers' Imprint, 13 (10): $1-16$.

Vaesen, Krist, Martin Peterson, and Bart Van Bezooijen. 2013. The reliability of armchair intuitions. Metaphilosophy, 44 (5): 559-578.

Weinberg, Jonathan M, Chad Gonnerman, Cameron Buckner, et al. 2010. Are philosophers expert intuiters? Philosophical Psychology, 23 (3): 331-355.

Wiegmann, Alex and Joachim Horvath. forthcoming. Intuitive Expertise in Moral Judgements. The Australasian Journal of Philosophy. https:/psyarxiv.com/5grsq/.

Williamson, Timothy. 2007. The Philosophy of Philosophy. Oxford: Blackwell.

- - - 2011. Philosophical expertise and the burden of proof. Metaphilosophy, 42 (3): 215229. 